\title{
Macrophage 11/-HSD-1 deficiency promotes inflammatory angiogenesis
}

\author{
Zhenguang Zhang1,*, Agnes E Coutinho1,†, Tak Yung Man', Tiina M J Kipari², \\ Patrick W F Hadoke', Donald M Salter ${ }^{2}$, Jonathan R Seckl1 and Karen E Chapman' \\ 1University/BHF Centre for Cardiovascular Science, The Queen's Medical Research Institute, The University of \\ Edinburgh, Edinburgh, UK \\ ${ }^{2}$ Centre for Genomic and Experimental Medicine, MRC Institute of Genetic and Molecular Medicine, \\ The University of Edinburgh, Western General Hospital, Edinburgh, UK \\ *(Z Zhang is now at AV Hill Building, Faculty of Life Science, University of Manchester, Manchester, UK) \\ ${ }^{\dagger}$ (A E Coutinho is now at Humber College Institute of Technology and Advanced Learning, Toronto, Canada)
}

Correspondence should be addressed to K E Chapman

Email

Karen.Chapman@ed.ac.uk

\begin{abstract}

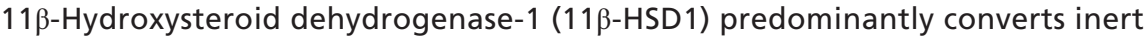
glucocorticoids into active forms, thereby contributing to intracellular glucocorticoid levels. $11 \beta$-HSD1 is dynamically regulated during inflammation, including in macrophages where it regulates phagocytic capacity. The resolution of inflammation in some disease models including inflammatory arthritis is impaired by $11 \beta$-HSD 1 deficiency or inhibition. However, $11 \beta$-HSD 1 deficiency/inhibition also promotes angiogenesis, which is beneficial in mouse models of surgical wound healing, myocardial infarction or obesity. The cell types responsible for the anti-inflammatory and anti-angiogenic roles of $11 \beta$-HSD 1 have not been characterised. Here, we generated Hsd11b1MKO mice with LysM-Cre mediated deletion of Hsd11b1 to investigate whether $11 \beta$-HSD 1 deficiency in myeloid phagocytes is pro-angiogenic and/or affects the resolution of inflammation. Resolution of inflammatory $\mathrm{K} / \mathrm{BxN}$-induced arthritis was impaired in Hsd11 b1MKO mice to a similar extent as in mice globally deficient in 11 $\beta$-HSD1. This was associated with >2-fold elevation in levels of the endothelial marker Cdh5 mRNA, suggesting increased angiogenesis in joints of Hsd11b1MKO mice following arthritis. A pro-angiogenic phenotype was confirmed by measuring angiogenesis in subcutaneously implanted polyurethane sponges, in which Hsd11 b1MKO mice showed $20 \%$ greater vessel density than their littermate controls, associated with higher expression of $C d h 5$. Thus, $11 \beta$-HSD 1 deficiency in myeloid phagocytes promotes angiogenesis. Targeting $11 \beta$-HSD1 in macrophages may be beneficial in tissue repair.
\end{abstract}

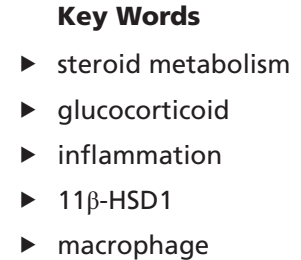

Journal of Endocrinology (2017) 234, 291-299

\section{Introduction}

Glucocorticoids exert anti-inflammatory effects both in vivo and in vitro. Whilst the potent effects of synthetic glucocorticoids have been widely exploited clinically to treat inflammatory disease, including rheumatoid arthritis, the role of endogenous corticosteroids in regulating inflammation is less well understood (Coutinho \& Chapman 2011).
Nevertheless, macrophages have emerged as a key target for the anti-inflammatory and immunomodulatory effects of endogenous glucocorticoids (Bhattacharyya et al. 2007, Tuckermann et al. 2007). Macrophages orchestrate much of the tissue remodelling that follows injury (Minutti et al. 2016) and play a key role in the angiogenesis that is 
important for tissue repair (Nucera et al. 2011). Macrophages are also important in the excessive or dysregulated angiogenesis that contributes to the pathogenesis of many chronic inflammatory diseases, a maladaptive response in rheumatoid arthritis (Jackson et al. 1997, Koch 1998).

Macrophages express 11ß-hydroxysteroid dehydrogenase type 1 (11ß-HSD1), a glucocorticoid metabolising enzyme that, in intact cells, converts the intrinsically inert cortisone and 11-dehydrocorticosterone into the active glucocorticoids, cortisol and corticosterone, respectively (Chapman et al. 2013b). 11ß-HSD1 thus amplifies glucocorticoid action. 11ß-HSD1 deficiency or inhibition alters inflammatory responses (Chapman et al. 2013a). 11ß-HSD1-deficient mice show more severe acute inflammation in thioglycollate-induced sterile peritonitis (Gilmour et al. 2006), following lipopolysaccharide (Zhang \& Daynes 2007), in carrageenan-induced pleurisy (Coutinho et al. 2012), in the K/BxN serum-induced model of inflammatory arthritis (Coutinho et al. 2012) and following coronary artery ligation in a model of myocardial infarction (McSweeney et al. 2010). Macrophages are implicated in the altered inflammatory responses of $11 \beta$-HSD1-deficient mice. In vitro, peritoneal or splenic macrophages from 11ß-HSD1deficient mice overproduce inflammatory cytokines following lipopolysaccharide stimulation (Zhang \& Daynes 2007). During thioglycollate-induced peritonitis, 11ß-HSD1deficient mice show a delay in the acquisition of phagocytic capacity by macrophages, though the inflammation resolves at a similar time to that in control mice (Gilmour et al. 2006). Reduced cholesterol accumulation in macrophages plays a role in the atheroprotective and anti-inflammatory effects of global 11ß-HSD1 deficiency or inhibition in atherosclerosis-prone Apoe $e^{-/}$mice (Garcia et al. 2013, Kipari et al. 2013, Luo et al. 2013). Following myocardial infarction, macrophages accumulate around the infarct zone more rapidly in 11ß-HSD1-deficient mice (McSweeney et al. 2010). They switch to a pro-reparative, pro-angiogenic ' $M 2$ ' phenotype earlier than in control mice, resulting in greater angiogenesis in the healing infarct and better recovery of heart function post-myocardial infarction (Small et al. 2005, McSweeney et al. 2010, Michailidou et al. 2012). Global 11ßHSD1 deficiency is also pro-angiogenic in other contexts: in the sponge implantation assay (Small et al. 2005); in adipose tissue of obese mice where it is associated with reduced adipose tissue hypoxia and inflammation (Michailidou et al. 2012) and in cutaneous surgical wounds, where it is associated with improved wound repair (Small et al. 2005).

Here, we have generated mice deficient in 11ß-HSD1 in myeloid phagocytes (Hsd11b1 ${ }^{\text {MKO}}$ ) to investigate the role of $11 \beta$-HSD1 activity in macrophages. We have used models of inflammation associated with a strong angiogenic response - the $\mathrm{K} / \mathrm{BxN}$ serum transfer model of inflammatory arthritis and the sponge implantation assay, in which the role of 11ß-HSD1 activity in macrophages is examined.

\section{Materials and methods}

\section{Animals}

All experiments on animals were carried out in accordance with the UK Home Office Animals (Scientific Procedures) Act of 1986 and European Directive 2010/63/EU, following approval by the University of Edinburgh Animal Welfare and Ethical Review Body. Mice were housed in groups (2-5 per cage) under controlled conditions: $12 \mathrm{~h}$ light/darkness cycle at $21^{\circ} \mathrm{C}$ with free access to standard rodent chow and water. $H s d 11 \mathrm{~b} 1^{\mathrm{ff} f}$ mice, with LoxP sites flanking exon 3 of the Hsd11b1 gene, were generated by TaconicArtemis (Cologne, Germany) onto a C57BL/6 background (Verma M, Kipari TMJ, Zhang Z, Man TY, Forster T, Homer NZM, Seckl JR, Holmes MC \& Chapman KE, unpublished observations). Hsd11b1мко mice with myeloid cell $11 \beta$-HSD1 deficiency were generated by crossing LysM-Cre (backcrossed to a C57BL/6 background (Cramer et al. 2003)) with $H s d 11 b 1^{f / f}$ mice. Experimental (Hsd11b1 ${ }^{\text {MKO})}$ and littermate control (Hsd11b1fff) mice were the offspring of male $H s d 11 b 1^{\text {MKO }}$ mice bred with female Hsd11b1f/f mice. Hsd11b1Del1/Del1 mice (Verma M, Kipari TMJ, Zhang Z, Man TY, Forster T, Homer NZM, Seckl JR, Holmes MC \& Chapman KE, unpublished observations) were generated from $H s d 11 b 1^{f / f}$ mice and are homozygous for a germline deletion of exon 3 of the $H s d 11 b 1$ gene. All experiments used male mice aged between 8 and 16 weeks.

\section{Peritoneal myeloid cell isolation and 11 $\beta$-HSD1 activity assay}

Mice were killed by $\mathrm{CO}_{2}$ asphyxiation. Resident cells were harvested from the peritoneum by lavage with $5 \mathrm{~mL}$ ice-cold PBS as previously described (Gilmour et al. 2006). Inflammatory cells elicited to the peritoneum $24 \mathrm{~h}, 72 \mathrm{~h}$ or $96 \mathrm{~h}$ following intra-peritoneal injection of thioglycollate $(0.2 \mathrm{~mL}, 10 \%)$ were collected by lavage with 5mL ice-cold PBS (Coutinho et al. 2016). At $24 \mathrm{~h}$, cells comprise mainly neutrophils and monocytes, whereas the population is predominantly macrophages at 72h and 96h (Melnicoff et al. 1989, Zhang et al. 2008,

Published by Bioscientifica Ltd. 
Coutinho et al. 2016). Where appropriate, neutrophils were isolated with anti-Ly6G antibody (clone RB6-8C5, Thermo Fisher Scientific) coupled to anti-rat IgG microbeads (Miltenyi Biotec Ltd., Bisley, Surrey, UK) by magnetic-activated cell sorting as described previously (Coutinho et al. 2016). Macrophages were purified by adherence to tissue culture plates using an established procedure that gives $>90 \%$ purity (Zhang et al. 2008). $11 \beta$-HSD1 activity in cultured cells was measured by addition of $5 \mathrm{nM}\left[{ }^{3} \mathrm{H}\right]$-11-dehydrocorticosterone to the medium, as described previously (Coutinho et al. 2016).

\section{K/BxN serum transfer-induced arthritis}

$\mathrm{K} / \mathrm{BxN}$ serum was generated in-house as described previously (Coutinho et al. 2012). To induce arthritis in mice, $100 \mu \mathrm{L}$ serum was injected intraperitoneally. Inflammation was scored daily for 21 days by an investigator blind to genotype. Scoring was carried out by visual examination according to a clinical index in which each joint was ascribed a score of $0-3$, as described previously (Coutinho et al. 2012). The combined scores of all 4 limbs were calculated for each mouse. For histology, joints were fixed in $10 \%$ formalin for 1 day and then decalcified in 10\% EDTA in neutral buffered formalin and paraffin embedded. Joint sections $(4 \mu \mathrm{m})$ were deparaffinised, hydrated and stained with haematoxylin and eosin for histopathological examination. The severity of pathological changes in the ankle joint was quantified on a scale of $0-3$ for each mouse, based on a scoring system modified from a previous protocol (Ruiz-Heiland et al. 2012). Briefly, the main pathological feature, synovium thickening, is assessed and assigned a score of 0 if there is no change compared to untreated, 1 if there is mild proliferation, 2 if there is extended proliferation and 3 if there is severe proliferation with tenosynovitis. RNA was extracted from the hind ankle joints using Trizol (Thermo Fisher Scientific) following pulverisation using a mortar and pestle, under liquid nitrogen.

\section{Sponge implant assay of angiogenesis}

Mice were anaesthetised with isoflurane, and a sterilized sponge cube measuring $1 \times 1 \times 1 \mathrm{~cm}$ (Caligen Foam, Accrington, Lancashire, UK) was implanted subcutaneously on each flank, as described previously (Small et al. 2005). After 21 days, mice were killed and sponges were removed. The sponge from the right flank was frozen at $80^{\circ} \mathrm{C}$ for later RNA extraction using Trizol (Thermo Fisher Scientific). The sponge from the left flank was fixed in 10\% formalin and embedded in paraffin. Sections were stained with haematoxylin and eosin for angiogenesis scoring. Vessel density was determined by Chalkley counting, as described previously (Small et al. 2005) by an investigator blind to experimental group. Briefly, a 25-point Chalkley eyepiece graticule (Graticules Ltd, Edenbridge, Kent, UK) was used to count blood vessels at $\times 250$ magnification. The graticule was placed so that the maximum number of graticule dots overlay with blood vessels. The average count values (3 random areas/section, 2 sections/sample) were recorded as vessel numbers.

\section{Immunohistochemistry}

Paraffin-embedded sections $(4 \mu \mathrm{m})$ were deparaffinised, blocked with $10 \%$ goat serum after antigen retrieval with citrate buffer ( $\mathrm{pH} \mathrm{6)}$ and incubated overnight with primary antibodies against isolectin IB4 (Alexa Fluor 488-conjugated isolectin B4, 1:100; I21411, Thermo Fisher Scientific) and $\alpha$-smooth muscle actin (anti-actin, $\alpha$-smooth muscle-Cy3 antibody, mouse monoclonal clone 1A4; C6198-100UL, Sigma-Aldrich) to detect endothelial cells and perivascular mural cells, respectively.

\section{Western blotting}

Peritoneal cells or purified Ly6G+ cells were homogenised in RIPA buffer (R0278, Sigma-Aldrich) supplemented with proteinase inhibitor cocktail (1:100 dilution; P8340, Sigma-Aldrich) and phosphatase inhibitor

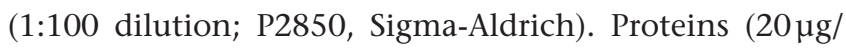
sample) were separated by electrophoresis on a $4-12 \%$ Bis-Tris gel (NP0323BOX, Thermo Fisher Scientific) and then transferred to a $0.4 \mu \mathrm{m}$ nitrocellulose membrane. Antibodies used for Western blotting recognise 11 $\beta$-HSD1 (raised in sheep and kindly provided by Dr Scott Webster, the University of Edinburgh (De Sousa Peixoto et al. 2008, Coutinho et al. 2016)), $\beta$-tubulin (MAB3408, Merck Millipore) and GAPDH (ab9485, Abcam).

\section{RNA analysis}

RNA (1 $\mu \mathrm{g})$ was reverse transcribed into cDNA using a SuperScript III Reverse transcriptase system kit (Thermo Fisher Scientific). Levels of specific cDNAs were measured by quantitative (q)PCR in triplicate, using a LightCycler 480 (Roche) and Universal Probe Library (UPL; Roche)based assays. Primer and probe information is shown in Supplementary Table 1 (see section on supplementary data given at the end of this article). A standard curve (c) 2017 The authors Printed in Great Britain
Published by Bioscientifica Ltd 
was prepared from pooled cDNA samples. Relative quantification was provided by LightCycler software using the maximum second derivative method and mRNA levels were normalised to an internal standard (chosen according to invariance between groups and validated against $18 \mathrm{~S}$ RNA); Tbp or Hprt, as indicated in figure legends.

\section{Statistics}

Values are means \pm standard error of means (s.E.M.). Data were analysed using GraphPad Prism 5.0. Unpaired t-tests (with Welch's corrections when variance was unequal), and one-way and two-way analysis of variance (ANOVA) were used, as appropriate. Significance was set at $P<0.05$.

\section{Results}

\section{Disruption of 11 $\beta$-HSD1 in resident macrophages}

To generate $H s d 11 b 1^{M K O}$ mice with disruption of $11 \beta$-HSD1 expression in myeloid phagocytes, LysM-Cre transgenic mice (Cramer et al. 2003) were crossed with mice in which exon 3 of the Hsd11b1 gene is flanked by LoxP sites (Hsd11b1f/f mice) (recombination strategy shown in Supplementary Fig. 1). LysM-Cre transgenic mice are reported to efficiently delete LoxP-flanked target genes in granulocytes and mature macrophages, with lower efficiencies in other myeloid cells (Clausen et al. 1999).
Measurement of $11 \beta$-HSD1 activity in myeloid cell populations from $H s d 11$ b1 $1^{\text {MKO }}$ mice showed an $89 \%$ decrease in 11 $\beta$-HSD1 activity in peritoneal resident cells, compared to Hsd11b1f/f littermate controls (Fig. 1A), consistent with the disruption of Hsd11b1 in this predominantly macrophage population (Clausen et al. 1999). In contrast, there was no significant reduction in $11 \beta$-HSD1 activity in thioglycollate-elicited peritoneal cells from Hsd11b1MKO mice collected $24 \mathrm{~h}$ (monocytes/ macrophages and neutrophils (Melnicoff et al. 1989, Coutinho et al. 2016)) or $96 \mathrm{~h}$ following thioglycollate injection (predominantly macrophages (Melnicoff et al. 1989, Zhang et al. 2008)) (Fig. 1B and C). Similarly, $11 \beta$-HSD1 activity was not significantly altered in purified neutrophils (Ly6G+ cells) from the peritoneum of thioglycollate-injected Hsd11b1 to littermate controls (Fig. 1D). 11 $\beta$-HSD1 activity was maintained in these myeloid cell populations despite the efficient reduction in Hsd11b1 mRNA levels (Supplementary Fig. 2). Western blotting confirmed a marked reduction in $11 \beta$-HSD1 protein levels in the resident peritoneal cell population of $H s d 11 b 1^{\text {MKO }}$ mice, but only a modest reduction in peritoneal cells collected $24 \mathrm{~h}$ or $96 \mathrm{~h}$ following thioglycollate injection and in purified neutrophils (Supplementary Fig. 3). These data suggest that the protein half-life of $11 \beta$-HSD1 exceeds the halflife of the thioglycollate-elicited monocyte/macrophage and neutrophil populations, but that 11 -HSD1 activity is markedly reduced in the longer-lived resident
A

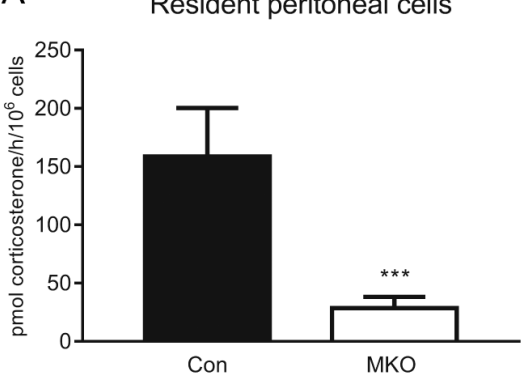

C

Peritoneal cells $96 \mathrm{~h}$ after TG injection

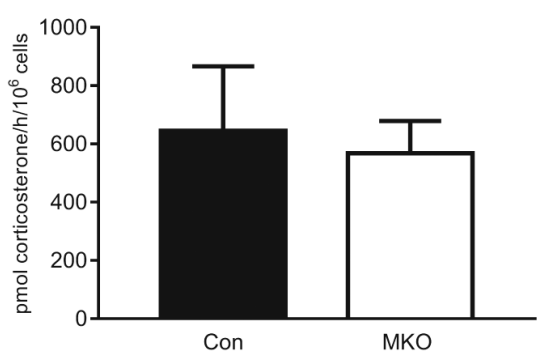

B
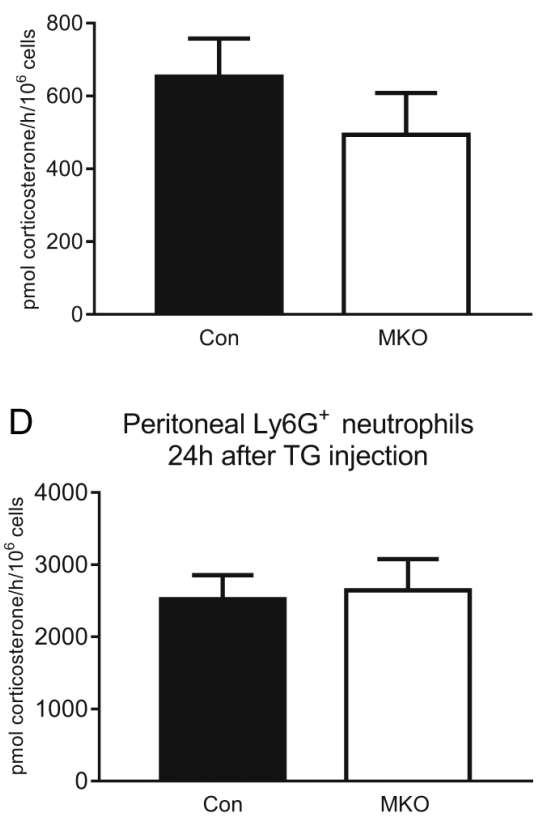

Figure 1

$11 \beta$-HSD1 activity is markedly reduced in resident peritoneal macrophages from $\mathrm{Hsd} 11 \mathrm{~b}$ 1 $\mathrm{\text {MKO }}$ mice. Resident peritoneal cells, or cells elicited to the peritoneum by i.p. injection of $0.2 \mathrm{~mL} 10 \%$ thioglycollate (TG), were harvested from Hsd11b1 1 мко (MKO: white bars) and control Hsd11b $1^{\text {tlf }}$ mice (Con: black bars). 11 $\beta$-HSD1 activity in peritoneal cells was measured by conversion of $\left[{ }^{3} \mathrm{H}\right]-11$-dehydrocorticosterone to corticosterone in resident peritoneal cells $(\mathrm{A})$ and in cells elicited to the peritoneum $24 \mathrm{~h}$ (B) or $96 \mathrm{~h}$ (C) following thioglycollate injection. Activity was also measured in purified neutrophils (Ly6G+ cells) isolated from the peritoneum $24 \mathrm{~h}$ after thioglycollate injection (D). 11 $\beta$-HSD1 activity is expressed as pmol corticosterone $/ \mathrm{h} / 10^{5}$ cells. Values are means \pm S.E.M. and were analysed by unpaired $t$-test $(n=3-8, * P<0.05)$. 
macrophage population. Given this, we sought to test the role of macrophage 11ß-HSD1 in models of inflammation in which the role of resident macrophages may be evident.

\section{Resolution of experimental arthritis is impaired in Hsd11b1Mко mice}

Tissue-resident macrophages have been implicated in the development and resolution of inflammatory arthritis in mice induced by injection of $\mathrm{K} / \mathrm{BxN}$ serum (Misharin et al. 2014). We therefore investigated whether macrophage $11 \beta$-HSD1 deficiency contributes to the more severe arthritis that develops in mice globally deficient in 11ß-HSD1 following injection of arthritogenic $\mathrm{K} / \mathrm{BxN}$ serum (Coutinho et al. 2012). Hsd11b1 ${ }^{\text {MKO }}$ mice did not replicate the earlier onset of arthritis seen previously with global 11ß-HSD1 deficiency (Coutinho et al. 2012). However,

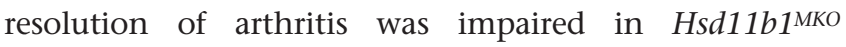
mice, compared to Hsd11b1fff controls (Fig. 2A and B). The course of the resolution phase in Hsd11b1 ${ }^{\text {MKO }}$ mice was very similar to that of Hsd11b1Del1/Del1 mice globally deficient in 11ß-HSD1 (Fig. 2A and B). Histopathological examination of the joints showed bone erosion and marked fibroproliferation in the synovium (Fig. 2C). Quantification of histopathology using a scoring index showed more marked histopathological changes in Hsd11b1 ${ }^{\text {мКO }}$ mice, compared to littermate controls (Fig. 2D).

Rheumatoid arthritis is associated with neoangiogenesis within the affected joint (Jackson et al. 1997, Koch 1998). Consistent with this, immunofluorescent staining of joints for the endothelial cell marker, isolectin IB4, and $\alpha$-smooth muscle actin ( $\alpha$-SMA), a marker of perivascular mural cells, revealed a high degree of vascularisation of the soft tissues of joints of both Hsd11b1 ${ }^{\text {MKO }}$ and control mice following $\mathrm{K} / \mathrm{BxN}$ serum transfer arthritis (Fig. 3A). However, qPCR measurement of $C d h 5$ mRNA encoding the endothelial marker, vascular endothelial (VE)-cadherin, showed $>2$-fold higher levels of $C d h 5$ mRNA in joints of $H s d 11 b 1^{\text {MKO }}$ mice, compared to littermate controls (Fig. 3B).

\section{Greater inflammatory angiogenesis in Hsd11b1 ${ }^{\text {мко mice }}$ following subcutaneous sponge implantation}

Increased levels of $C d h 5$ mRNA in joints of Hsd11b1MKO mice suggest an increase in neovascularisation of the joint
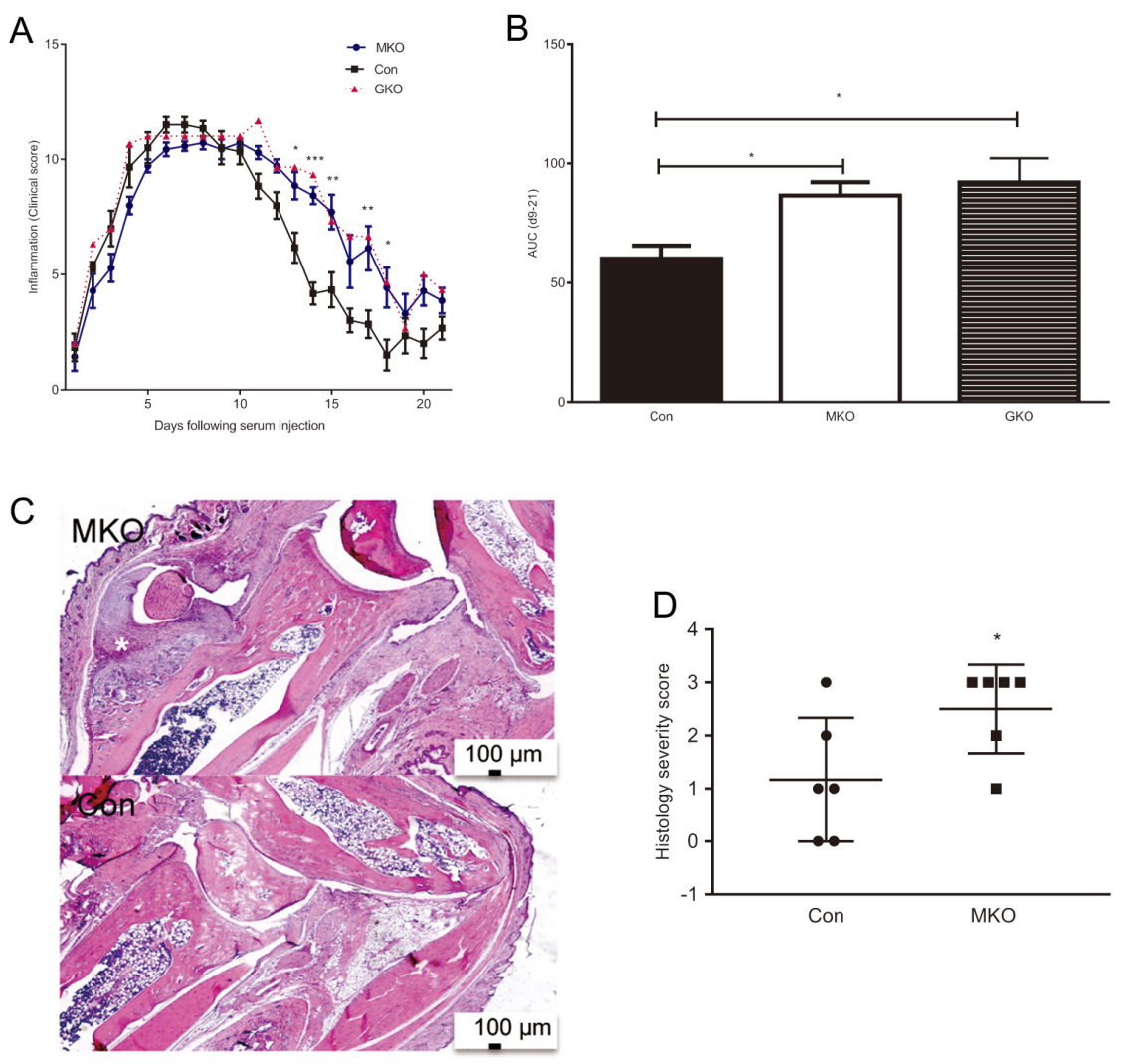

2017 The authors Printed in Great Britain
Figure 2

Resolution of K/BxN serum transfer-induced arthritis is impaired in Hsd11b1MKO mice. Arthritis was induced in Hsd11b1Del1/Del1 (global knockout, GKO: triangular symbols, $n=3)$, Hsd11b1мко (MKO: circular symbols/white bars, $n=6$ ) and control Hsd11b1 flf mice (Con: square symbols/ black bars, $n=7$ ) by i.p. injection of $100 \mu \mathrm{L} \mathrm{K/BxN}$ serum at day 0 . (A) Clinical scoring of joint inflammation over 21 days. Values are means \pm S.E.M. for Hsd11b1MкO and control Hsd11b1 fff mice. Data were analysed by two-way repeated measurement analysis of variance (ANOVA) with Bonferroni's multiple comparisons test; ${ }^{*} P<0.05, * * P<0.01, * * * P<0.001$. Only the mean value is shown for Hsd11b1Del1/Del1 mice. (B) The area under the curve (AUC) was calculated for the clinical score from days 9 to 21 (the resolution phase). Values are means \pm S.E.M. Data were analysed by one-way ANOVA $(P<0.01)$ with post-hoc Dunnett's multiple comparisons test with the Hsd11b1 flf group as control; ${ }^{\star} P<0.05$. (C) Representative sections of joints from $\mathrm{Hsd} 11 \mathrm{~b} 1$ Mко and $H s d 11 \mathrm{~b} 1^{\text {flf }}$ mice collected 21 days after injection and stained with haematoxylin and eosin showing tenosynovitis characterised by synovium hyperplasia, bone erosion and new bone formation. Scale bars, $100 \mu \mathrm{m}$. (D) Histopathological changes were quantified using a scoring index (see the 'Materials and methods' section for details) by an investigator blind to genotype. Values are means \pm S.E.M. Data were analysed by Mann-Whitney test, $n=6,{ }^{\star} P<0.05$. http://joe.endocrinology-journals.org DOI: 10.1530/JOE-17-0223
Published by Bioscientifica Ltd 


\section{A}
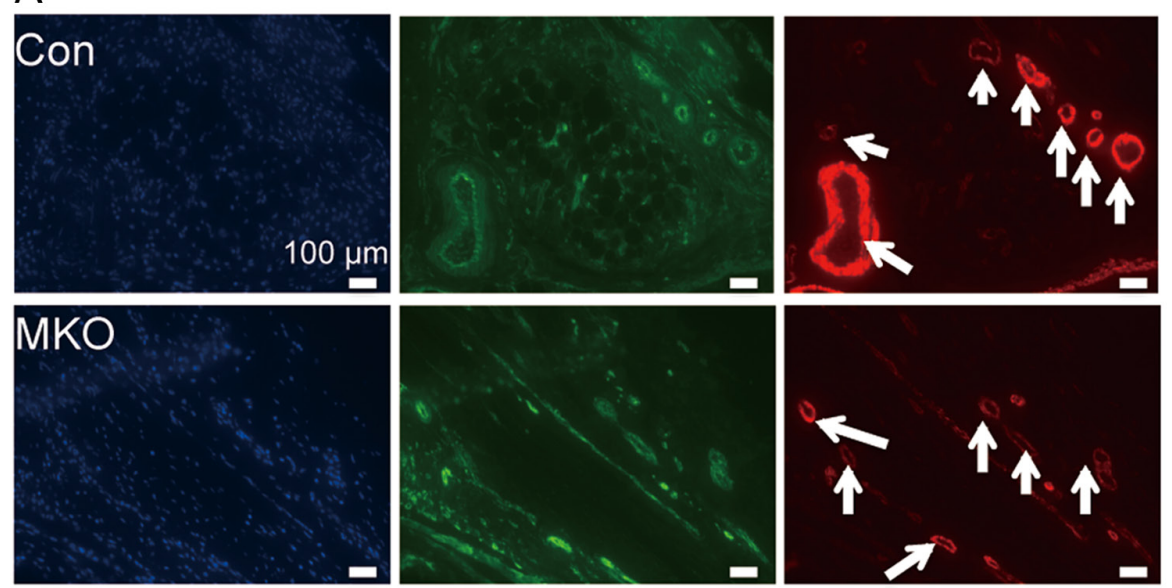

B

DAPI

Isolectin IB4

SMA

\section{Figure 3}

Higher $C d h 5$ expression suggests greater angiogenesis in the joints of Hsd11b1MKo mice. Arthritis was induced by i.p. injection of $100 \mu \mathrm{L} / \mathrm{BxN}$ serum, and the mice were killed 21 days later. (A) Immunofluorescent staining of blood vessels in the mesenchymal tissue of $H s d 11$ b1 MKO (MKO: top) and control mice (Con: bottom). From left to right: DAPI, isolectin B4, $\alpha$-SMA. (B) RNA was extracted from hind joints and qPCR used to measure levels of Cdh5 mRNA relative to Hprt, used as an internal standard. Values are in arbitrary units (AU) and are means \pm S.E.M. Data from Hsd11b1MKO (white bar) and Hsd11b1 flf mice (black bar) were analysed by unpaired $t$-test, $n=5-7, * P<0.05$.

during inflammatory arthritis. Mice with global 11 $\beta$-HSD1deficiency show greater inflammatory angiogenesis induced by subcutaneous sponge implantation (Small et al. 2005). To test whether macrophage $11 \beta$-HSD1 influences inflammatory angiogenesis, sponges were implanted subcutaneously in $H s d 11 b 1^{\text {MKO }}$ and littermate control mice, with angiogenesis assessed 21 days later (Figure 4A). Quantification of blood vessel density in sponges showed
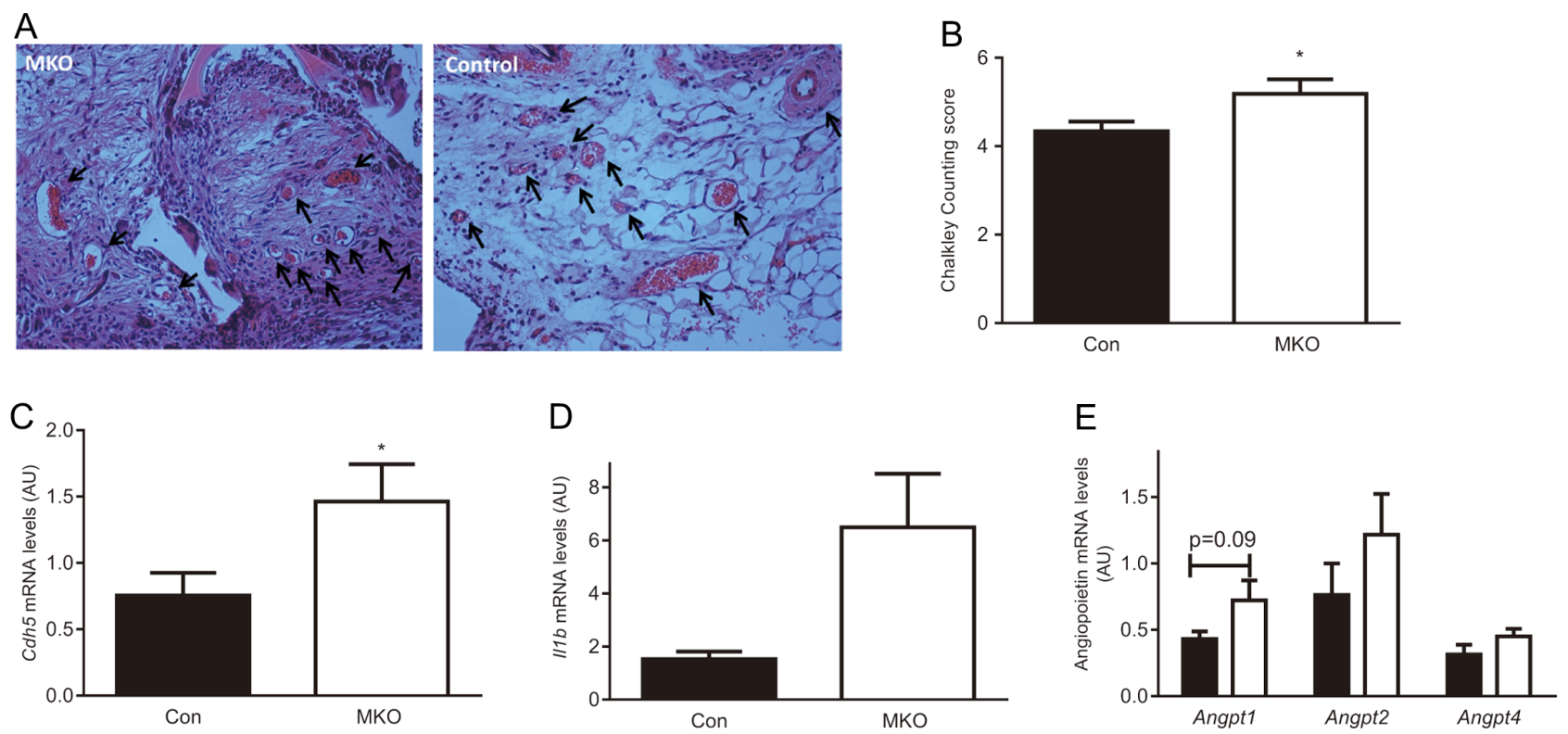

Figure 4

Compared to littermate controls, Hsd11b1мко mice show greater angiogenesis in the subcutaneous sponge implantation assay. (A) Representative images ( $\times 125$ magnification) of haematoxylin and eosin-stained sections of implanted sponges removed after 21 days, showing neovascularisation (blood vessels: arrows). (B) Quantification of blood vessel numbers by Chalkley counting. RNA was extracted from sponges removed 21 days after implantation, and qPCR was used to measure levels of: (C) Cdh5 mRNA, (D) I/1 mRNA, and (E) Angiopoietin-1, -2 and -4 mRNAs, relative to levels of Hprt mRNA, used as an internal standard (mRNA values in arbitrary units, AU). Values are means \pm s.E.M. Data from Hsd11b1MKO (MKO: white bars) and Hsd11b1fff mice (Con: black bars) were analysed by unpaired $t$-test $(A, B, C, E)$ or unpaired $t$-test with Welch's correction $(D)$; $* P<0.05, n=10-11$.

http://joe.endocrinology-journals.org
DOI: 10.1530/JOE-17-0223
(C) 2017 The authors Printed in Great Britain
Published by Bioscientifica Ltd 
$20 \%$ greater vessel density in $H s d 11 b 1^{\text {MKO }}$ mice (Fig. 4A and B) associated with almost 2-fold higher levels of $C d h 5$ mRNA (Fig. 4C). Levels of mRNA encoding IL-1 $\beta$, a proangiogenic cytokine (Voronov et al. 2003), were $>3$-fold increased in sponges from Hsd11b1 МКO mice (Fig. 4D) and there was also a trend for increased expression of mRNA encoding pro-angiogenic angiopoietins (Fig. 4E). Consistent with previous data from mice globally deficient in 11ß-HSD1 (McSweeney et al. 2010), increased angiogenesis in $H s d 11 b 1^{\text {MKO }}$ mice was not associated with a change in Vegfa mRNA levels, nor were levels of mRNA encoding several other cytokines altered (Supplementary Fig. 4). These data support a role for macrophage $11 \beta$-HSD1 in controlling angiogenesis and thus promoting the resolution of inflammatory arthritis.

\section{Discussion}

Our data in $H s d 11 b 1^{\text {MKO }}$ mice demonstrate that macrophages are a key cell type responsible for the proangiogenic phenotype conferred by 11/-HSD1 deficiency. This suggests that $11 \beta$-HSD1-mediated glucocorticoid regeneration within macrophages alters their phenotype to control an ongoing inflammatory response. In

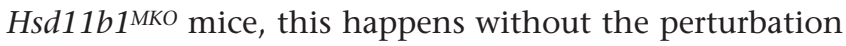
in the systemic ratio of active to inactive glucocorticoid levels that occurs with global 11ß-HSD1 deficiency (Harris et al. 2001; Verma M, Kipari TMJ, Zhang Z, Man TY, Forster T, Homer NZM, Seckl JR, Holmes MC \& Chapman KE, unpublished observations). Whether this is mediated by alterations in macrophage polarisation is currently unclear. However, in vitro, bone marrow-derived macrophages from $H s d 11 b 1^{-/-}$mice behave similar to wild type (Gilmour et al. 2006, Zhang \& Daynes 2007), suggesting the in vivo environment (and possibly substrate availability) is crucial to the physiological outcomes with $11 \beta$-HSD1 deficiency. This is suggested by evidence of an earlier macrophage polarisation to a pro-angiogenic ' $\mathrm{M} 2$ ' phenotype after myocardial infarction (McSweeney et al. 2010) and by higher expression of the M2 marker, SHIP1, in macrophages of $H s d 11 \mathrm{~b} 1^{-/}$mice than wild-type controls (Zhang \& Daynes 2007).

Whilst resident peritoneal macrophages from

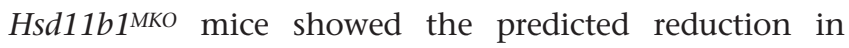
11ß-HSD1 activity and Hsd11b1 mRNA, our finding of near-normal 11 $\beta$-HSD1 protein and activity in myeloid cells recruited to the peritoneum of thioglycollate-injected Hsd11b1 ${ }^{\text {MKO }}$ mice, despite a marked reduction in the encoding mRNA, was unexpected. We have previously reported a discrepancy between 11ß-HSD1 protein/ activity and levels of the encoding $H s d 11 b 1$ mRNA in mouse neutrophils, with 11ß-HSD1 protein present despite little encoding mRNA (Coutinho et al. 2016). Other studies have noted similar discrepancies in other cell types (Bujalska et al. 2005, Chinetti-Gbaguidi et al. 2012). This suggests that in most myeloid phagocytes $11 \beta$-HSD1 protein has a long half-life and persists without renewal from ongoing mRNA translation, at least when inflammatory conditions prevail. The reduction in 11/-HSD1 activity in resident peritoneal macrophages but not in thioglycollate-elicited macrophages may reflect the longer life span of the resident macrophage population compared to recruited bone marrow-derived macrophages (Davies et al. 2013). Alternatively, the LysM-Cre transgene may be more highly expressed in resident macrophages. Expression of LysM/Lyz2, encoding LYSM, is known to be heterogeneous in macrophage populations (Faust et al. 2000, Hume 2011). In peritoneal cells, expression of LYSM is reportedly highest in large peritoneal macrophages that are highly phagocytic (Lichanska et al. 1999) and correspond to the resident population (Cain et al. 2013). This implicates resident macrophages in the pro-angiogenic phenotype seen with $11 \beta$-HSD1 deficiency. Resident macrophages are important in tissue repair. They efficiently clear apoptotic cells and actively promote revascularisation (Uderhardt et al. 2012, Wang \& Kubes 2016). Tissue-resident macrophages promote vessel anastomosis and thus vascular network complexity, acting downstream of vascular endothelial growth factor (VEGF)- $\alpha$ (Fantin et al. 2010). Our finding of unchanged expression of Vegfa in Hsd11b1 МКо compared to control mice (also unchanged in global 11ß-HSD1-deficient mice in a model of myocardial infarction (McSweeney et al. 2010)) is consistent with $11 \beta$-HSD1 acting in tissue-resident macrophages to restrain angiogenesis, downstream of VEGF- $\alpha$. However, VEGF signalling is regulated at the posttranslational level and further investigation is required to establish whether (or how) VEGF signalling is involved in the increased angiogenesis that occurs in Hsd11b1 mice. Our data also suggest resident macrophages are an important target of glucocorticoid action in the resolution of inflammation. However, it remains possible that, in addition to macrophages, other cell types contribute to the pro-angiogenic phenotype observed with global 11 $\beta$-HSD1 deficiency.

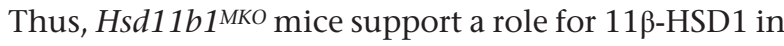
restraining and shaping the healing response orchestrated by resident macrophages in ischaemic or injured tissue. These mice will be a useful tool with which to dissect the contribution of macrophages to beneficial (or otherwise)

Published by Bioscientifica Ltd 
effects of 11 $\beta$-HSD1 in other models of tissue repair and/or chronic inflammation.

\section{Supplementary data}

This is linked to the online version of the paper at http://dx.doi.org/10.1530/ JOE-17-0223.

\section{Declaration of interest}

J R S holds patents on selective 11 $\beta$-HSD1 inhibitors. None of the other authors has a conflict of interest.

\section{Funding}

This work was supported by an MRC project grant (number 86642 ) and also by a Wellcome Trust programme grant (number 083184/Z/07/Z). Z Z was supported by a China Scholarships Council/University of Edinburgh Scholarship.

\section{Acknowledgements}

We are grateful to staff at the University of Edinburgh Central Bioresearch Services for assistance with animal care. We thank colleagues in the Centres for Cardiovascular Science and Inflammation Research for helpful advice and discussion.

\section{References}

Bhattacharyya S, Brown DE, Brewer JA, Vogt SK \& Muglia LJ 2007 Macrophage glucocorticoid receptors regulate Toll-like receptor-4mediated inflammatory responses by selective inhibition of p38 MAP kinase. Blood 109 4313-4319. (doi:10.1182/blood-2006-10048215)

Bujalska IJ, Draper N, Michailidou Z, Tomlinson JW, White PC, Chapman KE, Walker EA \& Stewart PM 2005 Hexose-6phosphate dehydrogenase confers oxo-reductase activity upon 11ß-hydroxysteroid dehydrogenase type 1. Journal of Molecular Endocrinology 34 675-684. (doi:10.1677/jme.1.01718)

Cain DW, O'Koren EG, Kan MJ, Womble M, Sempowski GD, Hopper K, Gunn MD \& Kelsoe G 2013 Identification of a tissue-specific, C/EBPbeta-dependent pathway of differentiation for murine peritoneal macrophages. Journal of Immunology 191 4665-4675. (doi:10.4049/jimmunol.1300581)

Chapman KE, Coutinho AE, Zhang Z, Kipari T, Savill JS \& Seckl JR 2013a Changing glucocorticoid action: 11 $\beta$-hydroxysteroid dehydrogenase type 1 in acute and chronic inflammation. Journal of Steroid Biochemistry and Molecular Biology 137 82-92. (doi:10.1016/j. jsbmb.2013.02.002)

Chapman KE, Holmes MC \& Seckl JR 2013b 11ß-Hydroxysteroid dehydrogenases: intracellular gate-keepers of tissue glucocorticoid action. Physiological Reviews 93 1139-1206. (doi:10.1152/ physrev.00020.2012)

Chinetti-Gbaguidi G, Bouhlel MA, Copin C, Duhem C, Derudas B, Neve B, Noel B, Eeckhoute J, Lefebvre P, Seckl JR, et al. 2012 Peroxisome proliferator activated receptor- $\gamma$ activation induces $11 \beta$-hydroxysteroid dehydrogenase type 1 activity in human alternative macrophages. Arteriosclerosis, Thrombosis, and Vascular Biology 32 677-685. (doi:10.1161/ATVBAHA.111.241364)

Clausen BE, Burkhardt C, Reith W, Renkawitz R \& Forster I 1999 Conditional gene targeting in macrophages and granulocytes using LysMcre mice. Transgenic Research 8 265-277. (doi:10.102 3/A:1008942828960)

Coutinho AE \& Chapman KE 2011 The anti-inflammatory and immunosuppressive effects of glucocorticoids, recent developments and mechanistic insights. Molecular and Cellular Endocrinology 335 2-13. (doi:10.1016/j.mce.2010.04.005)

Coutinho AE, Gray M, Brownstein DG, Salter DM, Sawatzky DA, Clay S, Gilmour JS, Seckl JR, Savill JS \& Chapman KE 2012 $11 \beta$-Hydroxysteroid dehydrogenase type 1 , but not type 2 , deficiency worsens acute inflammation and experimental arthritis in mice. Endocrinology 153 234-240. (doi:10.1210/en.2011-1398)

Coutinho AE, Kipari TM, Zhang Z, Esteves CL, Lucas CD, Gilmour JS, Webster SP, Walker BR, Hughes J, Savill JS, et al. 2016 $11 \beta$-Hydroxysteroid dehydrogenase type 1 is expressed in neutrophils and restrains an inflammatory response in male mice. Endocrinology 157 2928-2936. (doi:10.1210/en.2016-1118)

Cramer T, Yamanishi Y, Clausen BE, Forster I, Pawlinski R, Mackman N, Haase VH, Jaenisch R, Corr M, Nizet V, et al. 2003 HIF-1 $\alpha$ is essential for myeloid cell-mediated inflammation. Cell 112 645-657. (doi:10.1016/S0092-8674(03)00154-5)

Davies LC, Jenkins SJ, Allen JE \& Taylor PR 2013 Tissue-resident macrophages. Nature Immunology 14 986-995. (doi:10.1038/ni.2705)

De Sousa Peixoto RA, Turban S, Battle JH, Chapman KE, Seckl JR \& Morton NM 2008 Preadipocyte 11 $\beta$-hydroxysteroid dehydrogenase type 1 is a keto-reductase and contributes to diet-induced visceral obesity in vivo. Endocrinology 149 1861-1868. (doi:10.1210/ en.2007-1028)

Fantin A, Vieira JM, Gestri G, Denti L, Schwarz Q, Prykhozhij S, Peri F, Wilson SW \& Ruhrberg C 2010 Tissue macrophages act as cellular chaperones for vascular anastomosis downstream of VEGF-mediated endothelial tip cell induction. Blood 116 829-840. (doi:10.1182/ blood-2009-12-257832)

Faust N, Varas F, Kelly LM, Heck S \& Graf T 2000 Insertion of enhanced green fluorescent protein into the lysozyme gene creates mice with green fluorescent granulocytes and macrophages. Blood 96 719-726.

Garcia RA, Search DJ, Lupisella JA, Ostrowski J, Guan B, Chen J, Yang WP, Truong A, He A, Zhang R, et al. 2013 11ß-Hydroxysteroid dehydrogenase type 1 gene knockout attenuates atherosclerosis and in vivo foam cell formation in hyperlipidemic apoE(-/-) mice. PLOS ONE 8 e53192. (doi:10.1371/journal.pone.0053192)

Gilmour JS, Coutinho AE, Cailhier JF, Man TY, Clay M, Thomas G, Harris HJ, Mullins JJ, Seckl JR, Savill JS, et al. 2006 Local amplification of glucocorticoids by $11 \beta$-hydroxysteroid dehydrogenase type 1 promotes macrophage phagocytosis of apoptotic leukocytes. Journal of Immunology 176 7605-7611. (doi:10.4049/jimmunol.176.12.7605)

Harris HJ, Kotelevtsev Y, Mullins JJ, Seckl JR \& Holmes MC 2001 Intracellular regeneration of glucocorticoids by $11 \beta$-hydroxysteroid dehydrogenase (11 $\beta$-HSD)-1 plays a key role in regulation of the

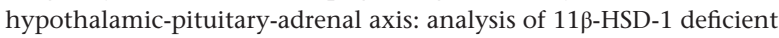
mice. Endocrinology 142 114-120. (doi:10.1210/endo.142.1.7887)

Hume DA 2011 Applications of myeloid-specific promoters in transgenic mice support in vivo imaging and functional genomics but do not support the concept of distinct macrophage and dendritic cell lineages or roles in immunity. Journal of Leukocyte Biology 89 525-538. (doi:10.1189/jlb.0810472)

Jackson JR, Seed MP, Kircher CH, Willoughby DA \& Winkler JD 1997 The codependence of angiogenesis and chronic inflammation. FASEB Journal 11 457-465.

Kipari T, Hadoke PW, Iqbal J, Man TY, Miller E, Coutinho AE, Zhang Z, Sullivan KM, Mitic T, Livingstone DE, et al. 2013 11ß-Hydroxysteroid dehydrogenase type 1 deficiency in bone marrow-derived cells reduces atherosclerosis. FASEB Journal 27 1519-1531. (doi:10.1096/ fj.12-219105)

Koch AE 1998 Review: angiogenesis: implications for rheumatoid arthritis. Arthritis and Rheumatology 41 951-962. (doi:10.1002/15290131(199806)41:6<951::AID-ART2>3.0.CO;2-D) 
Lichanska AM, Browne CM, Henkel GW, Murphy KM, Ostrowski MC, McKercher SR, Maki RA \& Hume DA 1999 Differentiation of the mononuclear phagocyte system during mouse embryogenesis: the role of transcription factor PU.1. Blood 94 127-138.

Luo MJ, Thieringer R, Springer MS, Wright SD, Hermanowski-Vosatka A, Plump A, Balkovec JM, Cheng K, Ding GJ, Kawka DW, et al. 2013 11ß-HSD1 inhibition reduces atherosclerosis in mice by altering pro-inflammatory gene expression in the vasculature. Physiological Genomics 45 47-57. (doi:10.1152/ physiolgenomics.00109.2012)

McSweeney SJ, Hadoke PW, Kozak AM, Small GR, Khaled H, Walker BR \& Gray GA 2010 Improved heart function follows enhanced inflammatory cell recruitment and angiogenesis in 11 $\beta$-HSD1deficient mice post-MI. Cardiovascular Research 88 159-167. (doi:10.1093/cvr/cvq149)

Melnicoff MJ, Horan PK \& Morahan PS 1989 Kinetics of changes in peritoneal cell populations following acute inflammation. Cellular Immunology 118 178-191. (doi:10.1016/0008-8749(89)90367-5)

Michailidou Z, Turban S, Miller E, Zou X, Schrader J, Ratcliffe PJ, Hadoke PW, Walker BR, Iredale JP, Morton NM, et al. 2012 Increased angiogenesis protects against adipose hypoxia and fibrosis in metabolic disease-resistant $11 \beta$-hydroxysteroid dehydrogenase type 1 (HSD1)-deficient Mice. Journal of Biological Chemistry 287 4188-4197. (doi:10.1074/jbc.M111.259325)

Minutti CM, Knipper JA, Allen JE \& Zaiss DM 2016 Tissue-specific contribution of macrophages to wound healing. Seminars in Cell and Developmental Biology 61 3-11. (doi:10.1016/j. semcdb.2016.08.006)

Misharin AV, Cuda CM, Saber R, Turner JD, Gierut AK, Haines GK 3rd, Berdnikovs S, Filer A, Clark AR, Buckley CD, et al. 2014 Nonclassical Ly6C(-) monocytes drive the development of inflammatory arthritis in mice. Cell Reports 9 591-604. (doi:10.1016/j.celrep.2014.09.032)

Nucera S, Biziato D \& De Palma M 2011 The interplay between macrophages and angiogenesis in development, tissue injury and regeneration. International Journal of Developmental Biology $\mathbf{5 5}$ 495-503. (doi:10.1387/ijdb.103227sn)
Ruiz-Heiland G, Horn A, Zerr P, Hofstetter W, Baum W, Stock M, Distler JH, Nimmerjahn F, Schett G \& Zwerina J 2012 Blockade of the hedgehog pathway inhibits osteophyte formation in arthritis. Annals of the Rheumatic Diseases 71 400-407. (doi:10.1136/ ard.2010.148262)

Small GR, Hadoke PW, Sharif I, Dover AR, Armour D, Kenyon CJ, Gray GA \& Walker BR 2005 Preventing local regeneration of glucocorticoids by $11 \beta$-hydroxysteroid dehydrogenase type 1 enhances angiogenesis. PNAS 102 12165-12170. (doi:10.1073/ pnas.0500641102)

Tuckermann JP, Kleiman A, Moriggl R, Spanbroek R, Neumann A Illing A, Clausen BE, Stride B, Forster I, Habenicht AJ, et al. 2007 Macrophages and neutrophils are the targets for immune suppression by glucocorticoids in contact allergy. Journal of Clinical Investigation 117 1381-1390. (doi:10.1172/JCI28034)

Uderhardt S, Herrmann M, Oskolkova OV, Aschermann S, Bicker W, Ipseiz N, Sarter K, Frey B, Rothe T, Voll R, et al. 2012 12/15-lipoxygenase orchestrates the clearance of apoptotic cells and maintains immunologic tolerance. Immunity 36 834-846. (doi:10.1016/j.immuni.2012.03.010)

Voronov E, Shouval DS, Krelin Y, Cagnano E, Benharroch D, Iwakura Y, Dinarello CA \& Apte RN 2003 IL-1 is required for tumor invasiveness and angiogenesis. PNAS 100 2645-2650. (doi:10.1073/ pnas.0437939100)

Wang J \& Kubes P 2016 A reservoir of mature cavity macrophages that can rapidly invade visceral organs to affect tissue repair. Cell $\mathbf{1 6 5}$ 668-678. (doi:10.1016/j.cell.2016.03.009)

Zhang TY \& Daynes RA 2007 Macrophages from 11ß-hydroxysteroid dehydrogenase type 1-deficient mice exhibit an increased sensitivity to lipopolysaccharide stimulation due to TGF- $\beta$ mediated up-regulation of SHIP1 expression. Journal of Immunology 179 6325-6335. (doi:10.4049/jimmunol. 179.9.6325)

Zhang X, Goncalves R \& Mosser DM 2008 The isolation and characterization of murine macrophages. Current Protocols in Immunology Chapter 14 Unit 14 11. (doi:10.1002/0471142735.im1401s83)

Received in final form 26 June 2017

Accepted 4 July 2017

Accepted Preprint published online 4 July 2017 (c) 2017 The authors Printed in Great Britain
Published by Bioscientifica Ltd. 